\title{
EDITORIAL
}

\section{Chicken or the egg? Critical illness and mental health}

\author{
Björn Weiss ${ }^{1}$ and Elizabeth Prince ${ }^{2^{*}}$ (1)
}

(0) 2021 Springer-Verlag GmbH Germany, part of Springer Nature

What came first, the chicken or the egg? Clinicians sometimes use this ancient Greek paradox to describe the problem of cause-and-effect in long-term impairments of survivors of critical illness-especially with regard to mental health disorders. What is evident is that surviving critical illness is associated with negative effects on cognition, mobility, and mental health; what has become known as Post-Intensive Care Syndrome (PICS). [1] Functional outcomes have become a fundamental patient-centered component of life-sustaining treatment success as functional decline is an unacceptable treatment price for many patients. [2] Understanding associations between psychiatric morbidity and critical illness is a vital step in developing interventions to optimize outcomes after critical illness.

Existing systematic reviews of critical illness survivors suggest that clinically significant symptoms of post-traumatic stress, depression, and anxiety are, respectively, seen in $20 \%, 30 \%$, and $35 \%$ of survivors. [3-6] Unsurprisingly, psychiatric morbidity prior to critical illness has emerged as one predictor of subsequent mental disorders and symptoms. [7] However, the understanding of prevalence and causal associations of mental disorders and critical illness remains limited by available research.

A core challenge in this research is establishing accurate mental health baselines preceding acute, unplanned intensive care unit (ICU) hospitalizations. Even in large well-controlled trials, investigators struggle to accurately estimate the pre-admission status of their participants. Pre-morbid mental health and functional abilities are typically obtained through third-party assessment

\footnotetext{
*Correspondence: lizprince@jhmi.edu

${ }^{2}$ Department of Psychiatry and Behavioral Sciences, DO Johns Hopkins University School of Medicine, Baltimore, MD, USA
}

Full author information is available at the end of the article in prospective trials. The frailty assessment from Brummel and colleague's work on functional outcome is one successful example. [8] In the ideal world, the assessment is performed by a proxy that has close contact to the patient, but reality often looks different. The resulting data are to be considered an estimate rather than a precise measurement.

In this issue of Intensive Care Medicine, Olafson and colleagues present a large population-based retrospective study of nearly 50,000 ICU patients examining treatment for mental disorders in the 5 years prior to and following critical illness. Treated prevalence of mental disorders before and after critical illness was compared with cohorts of non-ICU hospitalized patients and the general population. For the ICU patients, in the 5 years following critical illness, there was significant increase in treated prevalence of mental disorders from the 5 years prior, and compared to both cohorts. [9]

Most studies of mental health after critical illness utilize public health registries which opens them to various sources of bias, namely, quality of coding, underreporting of key outcomes, incorrect diagnoses, and misclassification. The use of treated prevalence, however, reflects care reality in "real-life" and it is no exaggeration to describe the documented prevalence of mental disorders described by Olafson and colleagues as catastrophic. An important caveat is that the data only reflect the situation in one Canadian province and absolute values cannot be generalized, but it should at least encourage clinical researchers to repeat this analysis in their own context.

The episodic nature of many mental disorders makes the extended 5-year period design especially strong. Considering Olafson's data, mental disorders are dynamic and treated prevalence changes in the 5 years prior to ICU admission nearly as much as post-discharge. There is an increased prevalence of mental disorders before and after critical illness, which dovetails

\section{Springer}


with findings from previous studies - the prevalence varies, but the data consistently show this signal. [10]

What is also unique about the work is that the authors did not limit their assessment to mood and anxiety disorders (including the comparably well-studied PTSD), but extended their research to treatment of other mental disorders, including psychosis and substanceinduced disorders. For future studies, this is extremely valuable as it extends the scope of mental health outcomes. The findings of this restrospective analysis show a demand for prospective studies to quantify and assess post-index admission outcomes in survivors of critical illness. To achieve this, we need to further implement core outcome measurement sets for PICS. [11]

For patients, the most important question might be if they have access to care and adequate critical care survivor therapy. This remains a true challenge for the future and is likely an unmet demand. Despite critical care being an interdisciplinary and multi-professional subject in the acute phase, critical care personnel (i.e., physicians and nurses) are usually cut off from subsequent healthcare. While ICU follow-up clinics do exist in some care models (e.g., United Kingdom), the majority of critical care survivors do not have access to ICU follow-up clinics [12-14]. PICS awareness in outpatient care has probably increased due to the coronavirus disease 2019 (COVID-19) pandemic and long-haul COVID-19. [15] While there is a greater scientific focus on specific COVID-19 consequences, Olafson's work shows that long-term mental health consequences are not a COVID-19-specific phenomenon at all. In addition, one observes that mortality after initial survival is extremely high, as nearly half of the cohort perished before follow-up time completion. The reduction in mental health burden over time might simply be the sad result of the high mortality.

In summary, Olafson and colleagues' study shows that mental health is a highly relevant topic in the context of intensive care. It is not so much about the "chicken or the egg," as it is the sheer magnitude of the problem and, consequently, need for prevention and intervention to ensure adequate care. We need a better understanding of the trajectory of mental health in the context of critical illness. To achieve better understanding, we must collaborate to (1) advocate and support a clinical follow-up for all ICU patients, (2) invest in further research, and (3) bolster awareness through education initiatives. Finally, intensive care is not only a matter of life and death but also of quality of life and adequate care for our patients. This paper requires us to focus more on mental health outcomes moving forward.

\section{Author details}

${ }^{1}$ Department for Anesthesiology and Intensive Care Medicine, CharitéUniversitätsmedizin Berlin, Corporate Member of Freie Universität Berlin and Humboldt Universität Zu Berlin, Campus Charité Mitte and Campus Virchow-Klinikum, Berlin, Germany. ${ }^{2}$ Department of Psychiatry and Behavioral Sciences, DO Johns Hopkins University School of Medicine, Baltimore, MD, USA.

\section{Acknowledgements}

None.

\section{Declarations}

\section{Conflicts of interest}

BW reports personal fees from Orion Pharma outside the submitted work. EP reports no conflicts of interest.

\section{Publisher's Note}

Springer Nature remains neutral with regard to jurisdictional claims in published maps and institutional affiliations.

Received: 15 September 2021 Accepted: 7 October 2021

Published online: 18 October 2021

\section{References}

1. Elliott D, Davidson JE, Harvey MA, Bemis-Dougherty A, Hopkins RO, Iwashyna TJ, Wagner J, Weinert C, Wunsch H, Bienvenu OJ, Black G, Brady S, Brodsky MB, Deutschman C, Doepp D, Flatley C, Fosnight S, Gittler M, Gomez BT, Hyzy R, Louis D, Mandel R, Maxwell C, Muldoon SR, Perme CS, Reilly C, Robinson MR, Rubin E, Schmidt DM, Schuller J, Scruth E, Siegal E, Spill GR, Sprenger S, Straumanis JP, Sutton P, Swoboda SM, Twaddle ML, Needham DM (2014) Exploring the scope of post-intensive care syndrome therapy and care: engagement of non-critical care providers and survivors in a second stakeholders meeting. Crit Care Med 42:2518-2526

2. Fried TR, Bradley EH, Towle VR, Allore H (2002) Understanding the treatment preferences of seriously ill patients. N Engl J Med 346:1061-1066

3. Parker AM, Sricharoenchai T, Raparla S, Schneck KW, Bienvenu OJ, Needham DM (2015) Posttraumatic stress disorder in critical illness survivors: a metaanalysis. Crit Care Med 43:1121-1129

4. Nikayin S, Rabiee A, Hashem MD, Huang M, Bienvenu OJ, Turnbull AE, Needham DM (2016) Anxiety symptoms in survivors of critical illness: a systematic review and meta-analysis. Gen Hosp Psychiatry 43:23-29

5. Rabiee A, Nikayin S, Hashem MD, Huang M, Dinglas VD, Bienvenu OJ, Turnbull AE, Needham DM (2016) Depressive symptoms after critical illness: a systematic review and meta-analysis. Crit Care Med 44:1744-1753

6. Jackson JC, Pandharipande PP, Girard TD, Brummel NE, Thompson JL, Hughes CG, Pun BT, Vasilevskis EE, Morandi A, Shintani AK, Hopkins RO, Bernard GR, Dittus RS, Ely EW (2014) Depression, post-traumatic stress disorder, and functional disability in survivors of critical illness in the BRAINICU study: a longitudinal cohort study. Lancet Respir Med 2:369-379

7. Prince E, Gerstenblith TA, Davydow D, Bienvenu OJ (2018) Psychiatric morbidity after critical illness. Crit Care Clin 34:599-608

8. Brummel NE, Bell SP, Girard TD, Pandharipande PP, Jackson JC, Morandi A, Thompson JL, Chandrasekhar R, Bernard GR, Dittus RS, Gill TM, Ely EW (2017) Frailty and subsequent disability and mortality among patients with critical illness. Am J Respir Crit Care Med 196:64-72

9. Olafson K, Marrie RA, Bolton JM, Bernstein CN, Bienvenu OJ, Kredentser MS, Logsetty S, Chateau D, Nie Y, Blouw M, Afifi TO, Stein MB, Leslie WD, Katz LY, Mota N, El-Gabalawy R, Enns MW, Leong C, Sweatman S, Sareen $J$ (2021) The 5-year pre- and post-hospitalization treated prevalence of mental disorders and psychotropic medication use in critically ill patients: a Canadian population-based study. Intensive Care Med. https://doi.org/ 10.1007/s00134-021-06513-z

10. Wunsch H, Christiansen CF, Johansen MB, Olsen M, Ali N, Angus DC, Sørensen HT (2014) Psychiatric diagnoses and psychoactive medication use among nonsurgical critically ill patients receiving mechanical ventilation. JAMA 311:1133-1142 
11. Spies CD, Krampe H, Paul N, Denke C, Kiselev J, Piper SK, Kruppa J, Grunow JJ, Steinecke K, Gülmez T, Scholtz K, Rosseau S, Hartog C, Busse R, Caumanns J, Marschall U, Gersch M, Apfelbacher C, Weber-Carstens S, Weiss B (2021) Instruments to measure outcomes of post-intensive care syndrome in outpatient care settings - results of an expert consensus and feasibility field test. J Intensive Care Soc 22:159-174

12. Haines KJ, Hibbert E, Leggett N, Boehm LM, Hall T, Bakhru RN, Bastin AJ, Butcher BW, Eaton TL, Harris W, Hope AA, Jackson J, Johnson A, Kloos JA, Korzick KA, Mactavish P, Meyer J, Montgomery-Yates A, Quasim T, Slack A, Wade D, Still M, Netzer G, Hopkins RO, Iwashyna TJ, Mikkelsen ME, McPeake J, Sevin CM (2021) Transitions of care after critical illness - challenges to recovery and adaptive problem solving. Crit Care Med 49(11):1923-1931. https://doi.org/10.1097/CCM.0000000000005095
13. Adrion C, Weiss B, Paul N, Berger E, Busse R, Marschall U, Caumanns J, Rosseau S, Mansmann U, Spies CD, (2020) Enhanced Recovery after Intensive Care (ERIC): study protocol for a German stepped wedge cluster randomised controlled trial to evaluate the effectiveness of a critical care telehealth program on process quality and functional outcomes. BMJ open 10: e036096

14. Cuthbertson BH, Rattray J, Campbell MK, Gager M, Roughton S, Smith A, Hull A, Breeman S, Norrie J, Jenkinson D, Hernández R, Johnston M, Wilson E, Waldmann C, (2009) The PRaCTICaL study of nurse led, intensive care follow-up programmes for improving long term outcomes from critical illness: a pragmatic randomised controlled trial. BMJ 339: b3723

15. Phillips S, Williams MA (2021) Confronting our next national health disaster-long-haul Covid. N Engl J Med 385:577-579 